\title{
Introspección e informes verbales en procesamiento humano de información
}

\section{Manuel Froufe Torres}

\author{
Universidad Autónoma de Madrid
}

\section{INTRODUCCION}

La discusión acerca de la validez de los informes verbales como datos que nos permiten descubrir los procesos cognitivos que subyacen a la conducta humana, pese a ser antigua en Psicología, sigue originando agudas controversias epistemológicas. De hecho, hasta principios de siglo, la introspectión analítica de la experiencia consciente constituía el principal método para hacer psicología empírica. Posteriormente, cuando la revolución conductista impuso la observación objetiva de la conducta manifiesta como únicos mérodo y objeto, respectivamente, legítimos de la Psicología, la introspección quedó desacreditada como método de investigación científica. Pese a todo, al reconocérsele cierta utilidad dentro de un contexto de descubrimiento, nunca ha llegado a desaparecer por completo. Y desde luego en psicología cognitiva, hoy más que nunca desde la condena de que fuera objeto por parte de los primeros conductistas, vuelve a hacer acto de presencia en numerosos trabajos. Por ejemplo, es corriente en la literatura sobre aprendizaje-memoria (Hunter, 1964; Luria, 1968) o sobre razonamiento y resolución de problemas (Newell y Simon, 1972; Quinton y Fellows, 1975; Hitch y Baddeley, 1976) interpretar el proceso cognitivo a la luz de las estrategias y datos verbalmente referidos por el sujeto. Aunque también es verdad, como veremos más adelante, que no todas las verbalizaciones de este tipo exigen introspección, en sentido clásico.

En cualquier caso, para saber cuándo los informes pueden aportar datos válidos, resulta indispensable delimitar la información de la que tenemos conciencia de aquella otra que no resulta accesible a nuestro conocimiento. $\mathrm{La}$ conciencia constituye la condición mínima para la introspección, y en general, para la validez de los informes verbales utilizados como datos que reflejan la realidad cognitiva subyacente. De lo contrario, resultaría que estaríamos pidiendo a los sujetos que informaran de algo de lo que ni siquiera habían tenido noticia.

No obstante, la validez de los informes verbales como datos no depende únicamente de que el sujeto tenga que referirse a experiencias de las que en su momento haya tenido conciencia. Depende también de otra serie de circunstancias (como el tiempo transcurrido entre la experiencia y la producción del informe, la necesidad de recodificar verbalmente la información, o de filtrarla, etc.), que pueden llegar a afectar vitalmente a la fidelidad del informe. Por eso, en el presente trabajo comenzaremos por el fenómeno de la experiencia consciente, para presentar a continuación (por 


\section{6}

considerarlo el más satisfactorio hasta la fecha) el modelo de Ericsson y Simon (1980) de producción de informes verbales y su utilización como técnica para obtener datos válidos en Psicología.

\section{CONCIENCIA}

Ningún psicólogo considera accesibles a la conciencia introspectiva todos los procesos cognitivos. Es obvio, por poner un caso, que no somos conscientes de los procesos que nos permiten ver un mundo tridimensional - simplemente lo vemos-. ¿Por qué, entonces, algunos procesos cognitivos se consideran accesibles a la conciencia y otros no? Mejor aún: ¿cuáles son los procesos cognitivos que utilizan o producen información de lo que tenemos conocimiento? ¿Se puede tener conciencia del proceso, o sólo de sus productos?

Recientemente, varios psicólogos cognitivistas (Miller, 1962; Neisser, 1967; Mandler, 1975; Evans, 1980 b) han sostenido que los sujetos humanos no tienen acceso directo, o lo tienen muy escaso, a sus procesos mentales superiores; únicamente existe conciencia de sus productos. Miller (1962) lo tiene muy claro: «es el resultado, y no el proceso, de pensar lo que aparece espontáneamente en la conciencia» (pág. 56). No obstante, ninguno de estos autores (salvo Evans, y referidos a una única tarea de razonamiento) cita datos relevantes en apoyo de su postura. El origen de la misma no está basado en investigaciones sobre procesos mentales superiores como los de razonamiento, resolución de problemas, toma de decisiones, etc., sino, más bien, en la investigación de procesos más básicos de percepción y memoria.

Por otra parte, hay evidencia de que ni los productos de los procesos cognitivos tienen por qué resultar siempre accesibles a la conciencia, ni los procesos mismos tienen por qué resultar siempre inaccesibles. Mientras en el caso de procesos automáticos rápidos, como el reconocimiento de palabras, puede darse $\operatorname{cog}$ nición sin conciencia de la palabra (Shiffrin y Schneider, 1977; Lundh, 1979), en el caso de procesos lentos y cognitivamente controlados como el razonamiento analógico, puede existir conciencia no sólo del producto final, sino también de etapas y contenidos intermedios, y en ocasiones también de las estrategias, reglas y operaciones mentales empleadas, es decir, del «proceso» (Schneider y Shiffrin, 1977; Sternberg, 1977; Morris, 1981 b).
Estudios

\section{a) Conciencia para el producto}

Con frecuencia, se supuso que percibir algo implicaba ser consciente de lo percibido. En opinión de Dixon (1981), «una razón de la resistencia para aceptar la posibilidad de percepción sin conocimiento es que, en las situaciones normales de vigilia, los procesos responsables de la representación fenoménica y los implicados en la mediación entre los estímulos externos y la conducta manifiesta, parecen trabajar como una unidad. Por eso, la naturaleza monolítica de su funcionamiento combinado, ha dado la impresión errónea de que, dado que se presentan inseparables, nunca puede tener lugar transmisión de información sin representación consciente» (pág. 10). Sin embargo, la postura más consistente con los datos actualmente disponibles, es la de que la capacidad del cerebro para registrar, procesar y transmitir información estimular, de ninguna forma es sinónimo de su capacidad para proporcionar experiencia perceptual consciente. Se trata de dos sistemas, uno para la transmisión de información, otro para la experiencia consciente, cuyo funcionamiento resulta relativamente independiente.

Por una parte, los estímulos que inciden en nuestro sistema de procesamiento pueden dar lugar a percepciones de las que no llega a existir representación consciente. La evidencia empírica a favor de este supuesto procede fundamentalmente, de dos tipos de experimentos: experimentos de percepción subliminal y experimentos de atención selectiva (discriminación preatencional). Inversamente, pueden aparecer contenidos en la conciencia basados en la memoria, y, por tanto, independientes del flujo sensorial inmediato. Tal es lo que ocurre en las alucinaciones (sean inducidas por deprivación sensorial, drogas o psicosis), en los sueños REM, en las sensaciones experimentadas por los sujetos que han visto repentinamente modificado de forma sustancial su esquema corporal, etc. No obstante, por constituir estas últimas circunstancias situaciones «especiales», nos ocuparemos sólo del primer aspecto: percepción sin conciencia de lo percibido.

\section{Percepción subliminal}

Se ha comprobado que aunque una señal estimular (o la razón señal/ruido) resulte de intensidad tan débil que el sujeto no pueda llegar a tener conocimiento de ella, sí puede determinar su respuesta. En 1951, Lazarus y McCleary (quienes acuñaron el término «sub- 


\section{Estudios}

cepción" para referirse a este fenómeno) condicionaron una respuesta galvánica de la piel a cinco sílabas sin sentido, emparejándolas repetidamente a electro-shocks; y a diferencia de otras sílabas sin sentido que no eran acompanadas de shock. A continuación, exposiciones muy breves de las sillabas produ jeron diferencias significativas en RPG entre las condicionadas y las no condicionadas, aun cuando los tiempos de exposición eran demasiado breves para permitir el reconocimiento de las sílabas presentadas.

Pronto, los resultados de una serie de experimentos que utilizaron como variable independiente la presentación subliminal de una variada gama de señales y como variable dependiente los juicios de magnitud (Black y Bevan, 1960; Boardman y Goldstone, 1962; Bevan y Pritchard, 1963) o las ilusiones de forma o magnitud (Smith y Henriksson, 1955; Farné, 1963; Worthington, 1964), apoyaron la existencia de percepción subliminal. Otro tanto ocurrió con algunos experimentos que basaron la presentación de señales subliminales en los principios de la estabilidad de la imagen retinal (Riggs y Whittle, 1967; Lehmann, Beeler y Fender, 1967) o de la rivalidad binocular (Cobb, Morton y Ettlinger, 1967; Harte, Seiple y Musso, 1974), y la existencia de procesamiento perceptual en el registro del potencial cortical evocado por aquellas señales. El potencial cortical evocado sigue presente cuando una imagen retinal estabilizada desaparece de la conciencia o cuando una imagen es suprimida de un ojo a través de la rivalidad binocular con el otro ojo. La deficiencia mayor en estos dos últimos paradigmas experimentales es la ausencia de indicios conductuales de esta supuesta percepción subliminal; en otras palabras, la falta de efectos de los estímulos subliminales sobre la cognición consciente.

Dicha limitación queda superada en los experimentos de enmascaramiento, en los que se analiza la influencia (sobre la percepción de un segundo estímulo) de un estímulo cuya presencia queda enmascarada precisamente por la presentación inmediata de ese segundo estímulo. Eagle (1959) intentó demostrar la posibilidad de percibir inconscientemente el estado de ánimo y carácter reflejados en una imagen humana enmascarada (y, por tanto, subliminal). Los sujetos tenían que juzgar la hostilidad de una silueta humana neutral, que era precedida inmediatamente por una brevísima exposición de esa figura dentro de una escena, bien en actitud agresiva, bien en actitud amable. Los sujetos juzgaron como más hostil la silueta cuando era precedida por la escena agresiva que cuando era precedida por la escena amable. Gracias a ciertas variaciones introducidas en una investigación posterior, Guthrie y Winer (1966) creyeron poder explicar los resultados de Eagle en función de las características de la memoria icónica (postefectos de la estimulación visual enmascarada), y por tanto sin necesidad de recurrir a la hipótesis de la percepción subliminal. Sin embargo, semejante reinterpretación no puede ser utilizada para explicar otros resultados obtenidos por Smith, Spence y Klein (1959). En este caso, la estimulación subliminal enmascarada consistía en la presentación muy breve de las palabras HAPPY o ANGRY intercaladas en la exposición de una cara delineada. También estos estímulos afectaron diferencialmente la estimación que los sujetos hacían del estado de ánimo de la cara.

Este experimento fue subsecuentemente replicado y perfeccionado por Somekh y Wilding (1973). Para asegurarse de que los sujetos no se enteraban de las palabras HAPPY y SAD, éstas eran presentadas por debajo del umbral a un ojo, en tanto el estímulo enmascarador, el rostro neutral, era simultáneamente presentado al otro ojo. Sus resultados confirmaron los obtenidos por Smith y cols. Además, encontraron un efecto adicional de interés considerable: cuando las palabras-indicio fueron sustituidas por los items estructuralmente similares HARRY y SAP, éstos no presentaron ningún efecto sobre la percepción del rostro neutral. Semejantes estímulos sólo fueron mal interpretados y leídos como HAPPY y SAD cuando fueron presentados supraliminalmente. Esto, además de desautorizar la hipótesis de los «indicios parciales» como explicación alternativa más parsimoniosa para este tipo de resultados experimentales (defendida, entre otros, por Bricker y Chapanis, 1953; Neisser, 1967), sugiere que, bajo algunas circunstancias, la discriminación inconsciente puede ser más precisa que la que ocurre bajo circunstancias de conocimiento. Quizá los efectos distorsionantes de la expectativa $y$ reestructuración que caracterizan a la percepción consciente no operan inconscientemente. Existen abundantes supuestos teóricos y algunos datos empíricos (Zuckerman, 1960; Spence y Holland, 1962; Posner, 1973; Shevrin y Dickman, 1980) que sugieren que los procesos cognitivos inconscientes pueden seguir principios de organización diferentes a los que rigen el procesamiento normal consciente.

Pese a la desconfianza y rechazo casi genera- 


\section{8}

les que siempre despertó el tema de la percepción subliminal, el hecho es que los experimentos más recientes, superando ciertas posibles deficiencias metodológicas como los "efectos del experimentador", las "características de demanda de la tarea", errores en la estimación del umbral, achacadas por diversos autores (Berstein y Eriksen, 1965; Guthrie y Wiener, 1966; Neisser, 1967) a algunos trabajos anteriores, apoyan la existencia de procesamiento semántico inconsciente. La evidencia proviene de diferentes paradigmas y modalidades sensoriales.

Bradshaw (1974) presentó visualmente a sus sujetos una palabra polisémica (v. gr. "palm») dispuesta entre otras dos, una a su izquierda y otra a su derecha. Una de estas palabras periféricas era desambigüizante para el ítem central. Inmediatamente después de la exposición de esta tríada tuvieron que elegir uno de los dos posibles significados del homógrafo. Un número significativo de estas respuestas demostró que el significado percibido de la palabra polisémica estaba sesgado por el "contexto» aportado por la palabra desambigüizante, aun cuando el sujeto no había podido enterarse de ella, dado que en el punto de fijación se encontraba el homógrafo y el tiempo de exposición era tan corto (125 mseg.) que no permitia ningún movimiento de rastreo (scanning) del ojo.

Henley y Dison (1974) pidieron a sus sujetos que relatasen las imágenes evocadas por la música presentada supraliminalmente a un oído, mientras al otro oído eran presentadas subliminalmente palabras referidas a cuatro categorías diferentes: tierra, agua, gente y animales. Aunque los sujetos no se enteraron de ninguna otra estimulación que no fuera la musical, las imágenes evocadas estaban significativamente influenciadas por las palabras-sugestión.

A partir de replicaciones, o introduciendo ciertas variaciones sobre los experimentos ya mencionados, Henley (1976), Marcel y Patterson (1978), Mykel y Daves (1979), obtuvieron también evidencia a favor de la existencia de análisis semántico inconsciente.

La elevada consistencia de los resultados pone la realidad de la percepción subliminal inconsciente, creemos, fuera de toda duda razonable. Eso quiere decir que aparte del umbral para las percepciones como tales, existe otro umbral diferente, y más alto que el anterior, para la conciencia introspectiva de las percepciones. En palabras de Lundh (1979), "los informes introspectivos acerca de lo per-

\section{Estudios}

cibido no nos dice nada acerca de lo que es percibido por el sujeto, sino acerca de aquello que el sujeto está introspectivamente consciente de haber percibido" (pág. 226).

\section{Discriminación preatencional}

Cuando a un sujeto se le presentan dos mensajes (v. gr., uno por cada oído) y se le obliga a que preste atención a uno de ellos (v. gr., pidiéndole que lo reproduzca en voz alta), generalmente el sujeto no tiene conocimiento del otro mensaje. Pero se ha comprobado que, no obstante, el mensaje no atendido ejerce cierta influencia sobre su conducta. Quiere esto decir que el mensaje secundario, aunque pase inadvertido para la conciencia del sujeto, es procesado en alguna medida.

Numerosos experimentos de escucha dicótica vienen a abundar en la idea, ya puesta de manifiesto a través del paradigma de la percepción subliminal, de la posibilidad de analizar semánticamente el material inconscientemente registrado (en el oído no atendido). Corteen y Wood (1972) comenzaron por asociar los nombres de algunas ciudades americanas a un shock, y a continuación los intercalaron en el material presentado por el canal no atendido en una prueba de escucha dicótica. Encontraron que dichos nombres producían un incremento significativo en la RPG palmar. Es más, incluso los nombres de ciudades que no habían sido asociados al shock inducían una RPG significativamente mayor que las palabras control; a pesar de que los sujetos no tenían conciencia de que en la fase de escucha dicótica les hubieran sido presentados nombres de ciudades. Todo ello sugiere la existencia de un nivel muy sofisticado de procesamiento sin que el sujeto llegue a tener siquiera conciencia del producto de ese proceso. Dado que el incremento de la RPG no se limitó a los nombres asociados al shock, no cabe explicar los resulrados en función de un simple procesamiento acústico de las palabras.

Para comprobar que no habia habido siquiera una conciencia momentánea de los nombres de ciudades incluidos en el mensaje secundario, Corteen y Dunn (1974) llevaron a cabo una prueba adicional. Se trataba de un experimento como el anterior, salvo que en lugar de preguntar al final de la prueba si habian oído algo por el canal no atendido, pidieron a los sujetos que presionasen una llave cada vez que oyesen un nombre de ciudad, por cualquier oído, durante el curso de la tarea de sombreado. En sólo una de 42 ocasiones en que hubo respuestas galvánicas significativas a 
las presentaciones críticas de nombres de ciudad, los sujetos mostraron conciencia; lo cual apoya la conclusión extraída en el primer experimento.

Unos años más tarde, sin embargo, Wardlaw y Kroll (1976) informaron de un intento fallido de replicar los resultados de Costeen y Wood (1972).

Evidencia favorable a la existencia de procesamiento semántico sin conciencia introspectiva la han obtenido también, en sendas investigaciones menos ambiguas que las anteriores, Von Wright y cols. (1975) y Foster y Gobier (1978), quienes mediante la RPG demostraron la ocurrencia de generalización a sinónimos y palabras acústicamente similares al estímulo condicionado, tanto si se presentaban en el mensaje atendido como en el no atendido. Foster y Govier comprobaron, además, que la probabilidad de obtener una RPG para las palabras acústicamente similares crecía si éstas últimas eran presentadas dentro de un contexto apropiado al estímulo condicionado, y esto a pesar de la falta de conocimiento de las palabras en el mensaje no atendido (que, para mejor garantizar su ignorancia, era presentado con una intensidad inferior). Por otra parte, estos autores creyeron poder explicar los resultados fallidos de Wardlaw y Kroll (1976) en base a defectos metodológicos, no siendo el menor el que su paradigma para producir RPGs condicionadas parecía casi garantizar la ausencia prácticamente total de condicionamiento.

El procesamiento de la información semántica sin conciencia de las palabras también fue puesto a prueba estimando el tiempo de reacción vocal a mensajes sombreados, mientras se hacía variar las características del mensaje no atendido. Para Henley (1976), «el tiempo de reacción constituye un indicador más sensiblè de los efectos de estímulos subliminales (o no atendidos) que las respuestas verbales" (pág. 566). Lewis (1970) encontró que las latencias de las respuestas de sombreado a palabras aisladas presentadas en el oído atendido aumentaban con la presentación simultánea de sinónimos en el oído, no atendido. La explicación alternativa de Broadbent y Gregory (1971), según la cual dicho efecto podría deberse a que quizá ambos oídos constituyen un canal de entrada único, queda descartada por los resultados de un nuevo experimento de Lewis (1972), en el que las presentaciones se hacen simultáneamente a un ojo y un oído. El sombreado de las palabras presentadas auditivamente también era inhibido por los sinónimos presenta- dos visualmente. Por razones, que no resultan claras, este efecto no se presentó cuando la condición fue invertida, es decir, cuando la atención se dirigió a la información visual.

Smith y Groen (1974) llegaron a la misma conclusión que Lewis sirviéndose de un método ligeramente distinto. En su experimento, los sujetos recibían presentación dicótica de listas de palabras, pudiendo pertenecer las listas atendida e «ignorada» a la misma o a diferentes categorías. A la presentación de cada par de listas seguía una prueba de recuerdo, con la instrucción de que los sujetos indicaran si la palabra-blanco había sido o no presentada en el oído atendido. Los errores y latencias de las respuestas a items que de hecho habian pertenecido a la lista no atendida, pero no a la atendida, resultaron significativamente mayores si dichos items pertenecían a la misma categoría que la de los items de la lista atendida; cosa que no ocurría si las palabras-blanco no habían formado parte de la lista no atendida. Esta respuesta inconsciente a la pertenencia a una categoría fue interpretada por Smith y Groen como indicio de que el material no atendido es sometido a algún análisis semántico.

Dentro del terreno visual, Underwood (1976) también detectó interferencia semántica producida por palabras no atendidas. Palabras colocadas periféricamente (que resultaban ignoradas por no ser atendidas) interferían con el nombramiento de imágenes colocadas en el punto central de la fijación visual. Resultados, por lo demás, equivalentes a los que posteriormente obtendrian Philppott y Wilding (1979) recurriendo a una técnica menos ambigua para garantizar la falta de conciencia. Philppott y Wilding encontraron que las latencias de las respuestas para nombrar colores, figuras o palabras presentadas a un ojo eran incrementadas cuando eran presentadas simultáneamente al otro ojo, por debajo del umbral de concienciación, palabras o figuras relacionadas, por su significado, con las primeras. Cuanto más próximas en significación ambas series de estímulos, mayor resultaba la interferencia.

Tomados en su conjunto, los experimentos de percepción subliminal y discriminación preatencional (los cuales recurriezon a paradigmas y métodos muy variados dentro de la estimulación auditiva y visual) evidencian la ocurrencia de pleno procesamiento semántico sin conciencia. Todo ello pone en conexión la conciencia para el producto del proceso cognitivo con la atención selectiva. Según los resul- 
tados de los mencionados experimentos, se puede concluir que tan sólo somos conscientes de aquellos productos perceptivos a los que atendemos selectivamente ( $\mathrm{y}$ que, por tanto, han de basarse en estimulación supraliminal); postura ésta compartida por numerosos autores: Miller (1962), Mandler (1975), Lundh (1979), Ruiz y Botella (1981), y en general -salvo Neisser (1980; Hirst y cols. 1980) - por casi todos los autores que investigaron la inatención selectiva. De hecho, en este tipo de experimentos, el informe introspectivo, a cualquier otro tipo de respuesta manifiesta voluntaria - que para el caso da lo mismo- ante el reconocimiento consciente de items, es usado como indicio de aquello a lo que se ha atendido selectivamente. Se dice que un sujeto ha atendido a un estímulo si manifiesta haber tenido conciencia de él; y a la inversa, si no manifiesta conciencia, se dice que no ha atendido al estímulo. En experimentos de escucha dicótica, por ejemplo, la respuesta de sombreado al oído atendido equivale a un informe de lo que ha sido concienciado. Pero si un item del mensaje a-ser-rechazado alcanza la conciencia del sujeto, se dice que éste ha captado su atención. En una palabra, atender es ser consciente de algo.

\section{b) Conciencia para el proceso}

Ya nos hemos referido a que, en el caso de procesos cognitivos lentos y controlados, el sujeto puede tener acceso consciente no sólo al producto final de ese proceso, sino también al proceso mismo. No obstante, en este contexto, el término «proceso" puede entenderse de dos formas: como etapas y contenidos experienciales intermedios, $\mathrm{o}$ como estrategias y reglas mentales utilizadas para alcanzar el producto final. Ambas concepciones son igual de legitimas.

\section{El proceso como contenido}

Acabamos de ver cómo la información semántica de palabras aisladas puede ser extraída sin que siquiera exista conciencia de haber percibido la palabra. No obstante, es de esperar que no todo pueda ser procesado preconscientemente. De hecho, MacKay (1973) encontró que mientras el significado de las palabras puede, en efecto, ser discriminado prea- tencionalmente, «las relaciones de estructura profunda entre palabras» exigen atención para ser comprendidas. Esto tiene una posible explicación. Según Shiffrin y Schneider (1977), sólo podrá ser discriminada preatencionalmente aquella información para la que el organismo, por encontrarse repetida e invariantemente expuesto a ello, haya desarrollado un procesamiento automático; el cual consiste en la activación, desencadenada por el input apropiado, de una secuencia de elementos configurada en la MLP. Como tal secuencia integrada en la MLP, no requiere para su actualización ni el control ni la atención por parte del sujeto. Eso significa que los procesos automáticos no sobrecargan la capacidad limitada del sistema humano de procesamiento de información, lo cual le permite llevar a cabo más de un proceso en paralelo. Pero esas mismas circunstancias impiden el acceso de la conciencia a los elementos integrantes del proceso.

Diferentes procesos cognitivos, como los de codificación perceptual o los de recuperación directa de información disponible en la MLP * (los cuales tienen lugar en decenas o centenas de mseg.), no parecen utilizar la MCP para almacenar etapas intermedias del procesamiento, sino sólo para el producto final. Generalmente, somos capaces de reconocer los rostros, las palabras o los objetos familiares directamente, sin necesidad de almacenar y manejar en la MCP las características del estímulo utilizadas para su discriminación. De igual forma, la recuperación de la memoria de información familiar, v. gr., el nombre de un antiguo amigo con el que hace tiempo no nos encontramos $\rightarrow a$ no ser que implique asociaciones sucesivas - suele tener lugar de forma repentina y sin que sepamos cómo ha ocurrido. En tales casos, sólo tenemos conciencia del producto final del proceso cognitivo.

Pero en circunstancias especiales, como las de percepción subliminal o discriminación preatencional, por existir un umbral más alto para la conciencia introspectiva de las percepciones que para las percepciones como tales, los procesos automáticos pueden incluso dar lugar a cognición sin que ni siquiera llegue a existir conciencia del producto del proceso. Por eso, es de esperar que una persona competente en una lengua, por haber estado reiteradamente expuesta al procesamiento casi inva-

* Según lo dicho, resulta obvio que en el modelo de procesamiento de información aquí adoptado (al igual que ocurre en el de Atkinson y Shiffrin, 1971, o en el de Ericsson y Simon, 1980) se identifica conciencia con información activada en la MCP; con independencia de que la MCP sea concebida como un almacén separado y especializado, o simplemente como la porción de la información en la MLP que está actual y temporalmente activada. 
riante de gran parte de las palabras que la integran, sea capaz de entender su significado sin necesidad de atenderlas ni de tomar conciencia introspectiva de ellas.

Es distinto con las frases que pueden construirse al combinar las palabras: continuamente escuchamos y producimos frases que nunca habiamos manejado antes. En este sentido, como señalara Chomsky (1965), nuestra competencia en una lengua desborda claramente nuestra experiencia de ella. Por eso la competencia y actuación al respecto no pueden descansar únicamente en el procesamiento preatencional automático. La mayor parte de las frases requieren lo que Schneider y Shiffrin (1977) denominan "procesamiento de información controlado».

Los procesos controlados consisten en la activación bajo control del sujeto de una secuencia de elementos que en gran parte han de ser manejados en la MCP, por lo que exigen la atención del sujeto. Ello determina que el sistema de procesamiento de información controlado resulte de capacidad limitada (posiblemente de naturaleza serial), pero permite asimismo que el sujeto tome conciencia no sólo del resultado final, sino también de etapas intermedias.

Por lo demás, en caso de que el sujeto se enfrente reiteradamente a una situación que, aun habiéndole exigido al principio un procesamiento controlado, requiera siempre la misma secuencia de respuestas y operaciones mentales, el procesamiento controlado acabará por convertirse en automático. Es precisamente esta automatización de los procesos cognitivos a que conduce la práctica, y que se produce a expensas de su control activo por parte del sujeto, y por tanto también a expensas de su flexibilidad, la que los sustrae de la conciencia. Semejantes efectos de la automatización los explican Ericsson y Simon (1980) en los siguientes términos: «antes de que haya tenido lugar un sobreaprendizaje, los procesos tienen que ser interpretados, con gran retroalimentación desde etapas intermedias de procesamiento almacenadas en la MCP. El sobreaprendizaje equivale a compilar estos procesos de tal manera que se llevan a cabo menos comprobaciones cuando aquellos son ejecutados, por eso se almacena en la MCP menos información referente a etapas intermedias. $\mathrm{La}$ experiencia con la compilación en lenguajes para computadora muestra que la automatización incrementa en gran medida la velocidad del proceso, a expensas de su flexibilidad, y sus etapas intermedias resultan menos disponibles para informe (verbal)» (págs. 236-237).

Una distinción similar a la de Schneider y Shiffrin (1977) entre procesos controlados y procesos automáticos es la diferenciación de Schank y Abelson (1977) entre plans y scripts. Ellos entienden que el procesamiento con plan resulta fundamentalmente consciente. Cualquier lector que practique la mecanografía y conduzca automóvil puede verificar de manera informal estos argumentos. Mientras se está adquiriendo la habilidad, la tarea resulta difícil y pesada, pero se pueden en gran medida controlar conscientemente todas las actividades implicadas, y por tanto informar de qué se hace y para qué. Cuando se desarrolla una habilidad de este tipo, crece la fluidez con que se ejecuta la tarea, pero disminuye el control consciente de la misma; hecho, por lo demás, defendido e investigado por Watt, y otros autores, ya a principios de siglo.

Naturalmente, aunque la dicotomía proceso controlado-proceso automático puede entenderse como una distinción cualitativa, inicialmente, la transformación de un proceso controlado en automático es meramente cuantitativa y progresiva. La adquisición de habilidades como las mencionadas puede interpretarse en términos del desarrollo de un procesamiento de información automático que "permite al organismo aprender modos cada vez más complejos de procesamiento de información mediante la construcción de subsistemas automáticamente aprendidos» (Shiffrin y Schneider, 1977, pág. 162). Aunque eso sí, puede llegar el momento en que preguntado, por ejemplo, un mecanógrafo por la ubicación de un signo dentro del teclado, es incapaz de responder verbalmente: se diría que el conocimiento está «en los dedos». El sobreaprendizaje de una habilidad la convierte en un proceso rutinario, fácil y específicamente-situacional. No requiere integración de nueva información, por tratarse de respuestas desarrolladas «para configuraciones estimulares particulares». De esta forma, lo que inicialmente es una cuestión de gradación cuantitativa puede acabar por dar lugar a una diferencia cualitativa. Considerados los casos extremos, resulta que lo que era accesible a la conciencia del novato, no lo es a la del experto, con todas las implicaciones que esto comporta.

Según todo lo que acabamos de decir, resulta que sólo tendremos conciencia - y por tanto únicamente podremos dar verbalmente cuenta de-los procesos cognitivos implicados 
en la ejecución de tareas nuevas y complejas, que por lo mismo resultarán de evolución lenta.

Aparte de las observaciones informales a las que ya nos hemos referido, existen algunas investigaciones experimentales que demuestran que mientras los procesos cognitivos implicados en tareas fáciles y rutinarias apenas resultan accesibles a la conciencia, los implicados en tareas nuevas y complejas sí lo son. Dean y Martin (1966) encontraron que conforme crece el aprendizaje de una lista de pares asociados, decrece el número de asociaciones mediacionales de las que se puede informar. El sobreaprendizaje de una lista durante 10 ensayos extra, por parte de los sujetos de un grupo experimental, dio lugar a un decremento significativo de mediaciones de las que tuvieron conciencia. Esto indica que cuando, debido a la práctica, se desarrolla un procesamiento automático, desaparecen contenidos intermedios del proceso cognitivo, o al menos la conciencia de dichos contenidos.

Rees e Israel (1935) demostraron que, ante una larga serie de anagramas con soluciones múltiples, los sujetos pueden llegar a elegir una solución con la misma estructura para todos los problemas, sin llegar a ser conscientes de dicha estructura; pero esto ocurría sólo cuando la solución requería una reestructuración sencilla (la simple permutación 54123 ), pero no cuando era necesaria una permutación más compleja de las letras. Parece razonable pensar que, en el primer caso, los sujetos desarrollaron un "set» que, por implicar una reestructuración tan sencilla, les permitía responder a través de un proceso "automático» que no exigía ni tomar conciencia de estados intermedios ni de la estructura de la solución. Sin embargo, cuando la reestructuración requerida para la solución era más compleja, el tratamiento dado a los elementos del problema permitía a los sujetos darse cuenta de la similitud de los anagramas. Semejante interpretación parece avalada por la comprobación de Sargent (1940) de que los su jetos, cuando encuentran soluciones rápidas a anagramas, son incapaces de informar de estados intermedios.

Quinton y Fellows (1975) encontraron que en problemas de series de tres términos, con la práctica, los sujetos trasladaban su atención desde el significado de la información semántica presentada, hacia el reconocimiento de caracteristicas perceptuales invariantes del desplegado estimular; o hacia propiedades puramente formales de la información presentada (Wood y Shotter, 1973). Determinada por este tipo de transición, Wood, Shotter y Godden (1974) encontraron evidencia empirica más directa de la pérdida de los contenidos intermedios, al obtener una marcada relación negativa entre la habilidad de los sujetos para responder preguntas inesperadas -que requerían conciencia de la información presentaday la práctica.

Un hecho que parece ir en contra de la supuesta conciencia para las etapas y contenidos integrantes del proceso cognitivo que tiene lugar en la realización de tareas nuevas y complejas, es el reflejado en observaciones y anécdotas en torno a la creatividad y resolución de problemas que tiene lugar a través de un proceso de insight o «iluminación repentina». Según la postura clásica (Wallas, 1926), en tales circunstancias, la iluminación de la idea creativa tendría lugar después de un período de trabajo inconsciente (incubación), que seguiria a un procesamiento previo para comprender y familiarizarse con el problema (preparación). De acuerdo con esta explicación, el hecho de que durante el período de incubación el sujeto se ocupe de otras cosas, permite que se desarrolle un proceso inconsciente de resolución.

Sin embargo, Woodworth (1938), basado fundamentalmente en un experimento de Plott y Baker, sugiere que durante este período de incubación el sujeto retorna ocasional y esporádicamente a ocuparse del problema, aun cuando la tarea primordial en ese momento sea precisamente otras cuyas demandas suelen interrumpir abruptamente el intento de proceso resolutorio. A partir de estas interrupciones esporádicas, Simon (1979) propone una explicación de la incubación basada en el funcionamiento habitual del sistema de procesamiento de información (establecimiento y reestructuración de metas, pérdida de la información en la MCP y recuperación y uso de la información en la MLP) sin necesidad de proponer un mecanismo especial para el pensamiento creativo. Según esta explicación, el proceso creativo no sería precisamente un proceso inconsciente y repentino; lo que ocurre es que los testimonios recogidos al respecto, al ser poco controlados y retrospectivos (memorias y entrevistas realizadas después que ha transcurrido un considerable lapso de tiempo desde el descubrimiento), suelen dar la impresión de que la comprensión tuvo lugar de una forma repentina, al olvidar los sujetos los pasos, asociaciones y etapas que progresivamente les habían llevado a la solución.

Sin duda, la utilización formal más convincente de la suposición de que, en tareas nuevas 
y complejas, los sujetos tienen conciencia de los contenidos y etapas integrantes del proceso cognitivo es la aportada por Newell y Simon (1972) al establecer el proceso resolutorio de problemas de lógica, ajedrez y criptoaritmética a partir de los protocolos producidos por los sujetos mientras «piensan en voz alta». A partir de semejantes datos verbales, los autores pudieron establecer las diferentes metas y estados de conocimiento (al menos en su mayor parte) generados durante el intento de solución; e incluso, a través del "gráfico del comportamiento en el problema", pudieron reconstruir visualmente la dinámica cronológica de la secuencia de «operadores» que van dando lugar a los diferentes y múltiples estados de conocimiento. De esta forma, Newell y Simon han podido ir mucho más allá de la cruda medición de si los sujetos resuelven o no el problema, o del tiempo invertido hasta conseguirlo, que sería casi todo lo que se podría lograr en caso de rechazar los informes verbales. De hecho, después del profundo análisis de los procesos resolutorios realizado por Newell y Simon, nadie parece discutir la utilidad de su método ni los supuestos en que se basa.

Byrne (1977) y Williams y Hollan (1981) recurrieron también a esta técnica de análisis de protocolos producidos por los sujetos mientras realizaban dos tareas más representativas de la vida cotidiana: planificar el menú para la comida de una fiesta, en la primera investigación, y recordar los nombres de los antiguos compañeros de colegio, en la segunda. En ambos casos, los autores creyeron obtener un registro aceptable de gran parte de los contenidos y momentos por los que iba transcurriendo la realización de la tarea, y de las que el sujeto debía ser consciente.

\section{El proceso como estrategia}

Es evidente que el árbol de búsqueda representado por Newell y Simon (1972) en el gráfico del comportamiento en el problema no constituye el proceso resolutorio, entendido el "proceso" como un conjunto de estrategias y reglas que nos dicen cómo, cuándo y porqué son puestas en acción las diferentes operaciones mentales. Eso lo saben bien Newell y Simon cuando defienden que la teorización acerca de las causas y consecuencias de la aplicación de los diferentes operadores a los distintos estados de conocimiento debe ser llevada a cabo por el experimentador, no por el propio sujeto. Es el experimentador quien, a partir del protocolo verbal, debe inferir las reglas que nos dicen qué condiciones desencadenan las diferentes acciones. A semejante conjunto de reglas lo denominan Newell y Simon sistema de producción.

Es principalmente en este sentido en el que algunos autores consideran que los sujetos no tenemos acceso introspectivo a nuestros procesos mentales. Evans (1980 a), por ejemplo, distingue entre lo que él denomina informes fenoménicos e informes de estrategias. Un informe de estrategia se diferencia de un informe fenoménico, según él, «en que al sujeto se le pide que describa no qué experimenta, sino cómo o por qué realizó una tarea cognitiva particular» (pág. 232). Evans (1980 b) argumenta que «los informes verbales constituyen una forma de datos con derecho a ser explicados en sí mismos, no cómo medios para explicar algún otro aspecto de la conducta. Los problemas surgen cuando dejamos de considerar los informes como una de las variables dependientes (...) y comenzamos a considerarlos como descripciones de los procesos que subyacen» (pág. 280).

Evans se basa fundamentalmente en dos investigaciones sobre razonamiento realizadas por él y Wason (Wason y Evans, 1975; Evans y Wason, 1976). En estos estudios se trabajó con la tarea de selección de Wason en que a los sujetos se les presentan cuatro tarjetas, de las que saben que cada una tiene un número por un lado y una letra por el otro. En el primer experimento (Wason y Evans, 1975), les presentaban a los sujetos estas dos reglas: 1 . " $\mathrm{Si}$ hay una (letra específica) en una cara de la tarjeta, entonces habrá un (número específico) en la otra cara»; 2. Si hay una (letra específica) en una cara de la tarjeta, entonces no habrá un (número específico) en la otra cara». La tarea consistia, lógicamente, en dar la vuelta a las tarjetas necesarias, y sólo a las necesarias, para comprobar si la correspondiente regla era verdadera o falsa. Los sujetos fueron sometidos a prueba para ambas reglas de forma contrabalanceada para el orden. Además, se les pedía que escribieran la razón por la que daban la vuelta o no a cada tarjeta. Las caras visibles de las cuatro tarjetas mostraban: una la letra $(\mathrm{L}+)$, otra el número $(\mathrm{N}+)$, especificados en la regla; otra, otra letra $(\mathrm{L}-)$, y otra, otro número $(\mathrm{N}-)$, distintos a los mencionados en la regla.

Para verificar ambas reglas, la mayor parte de los sujetos levantaban las tarjetas que presentaban $\mathrm{L}+$ y $\mathrm{N}+$ a la vista, hecho que constituye la selección correcta para la regla negativa (2), pero no para la positiva (1). Además, va- 


\section{4}

rios sujetos que comenzaron con la tarea negativa dieron razones que sugerían un intento de falsificar dicha regla negativa, lo que aparentemente denotaba una perfecta comprensión del problema. Sin embargo, sus razones para justificar la misma elección ante la regla positiva, en opinión de Wason y Evans, no eran clasificables como intentos de falsificación. Evans (1980 b) argumenta que «dado que cualquier definición razonable de insight (...) requiere transferencia a problemas de estructura similar, es difícil aceptar que el primer protocolo (a la regla negativa) refleja un insight genuino. La alternativa obvia es que el protocolo es una racionalización construida post boc para que cuadre a la conducta y a las instrucciones" (pág. 291).

En el segundo experimento, Evans y Wason (1976) creen aportar más evidencia a favor de esta hipótesis. Comprobaron que los sujetos justifican con la misma confianza cualquier conjunto de selección de tarjetas a levantar - con independencia de su corrección-si dichas selecciones se les presentan como respuestas «correctas». En este experimento, los sujetos no tenían que resolver la tarea de selección, sino que, en grupos independientes, se les presentaban cuatro soluciones distintas a la regla positiva. Aunque todas las soluciones se presentaban como «correctas», tres de las cuatro eran falsas. La tarea de los sujetós consistía en justificar la solución que se les había presentado y expresar el grado de confianza en cada razón que aportaban. Se comprobó que tendian a encontrar razones para justificar cualquier solución que les fuera presentada, y además, generalmente, manifestaban un alto grado de confianza en la corrección de sus razones.

Basados en tales observaciones, Wason y Evans (1975; Evans y Wason, 1976; Evans, 1980 a y b) proponen una teoría dual para explicar la actuación en tareas de razonamiento. En primer lugar, existe un proceso (A) noverbal, que determina nuestra actuación a la hora de realizar las respuestas, y que no resulta generalmente accesible a la introspección. Suele existir, además, otro proceso $(B)$, que opera a un nivel consciente y que, por tanto, puede ser aportado por el sujeto como la razón de su actuación. El hecho de que en la tarea de selección con proposición condicional en la que se niega el consecuente coincidan los resultados del proceso $A$ (tendencia a seleccionar las tarjetas que presentan a la vista los signos nombrados en la proposición -matching bias-) con los que ocurrirían en caso de haber primado el proceso $B$ manifestado por el sujeto, da la impresión de que éste hizo la selección correcta gracias a una comprensión cabal del problema. Sin embargo, de la justificación aportada por los sujetos para las respuestas dadas a la proposición que no niega el consecuente, así como de sus justificaciones a las soluciones incorrectas que se les proporcionaban en el segundo experimento, puede deducirse que en aquella ocasión se trataba de una coincidencia espuria, producto de un artefacto experimental. Para Evans y Wason, ello demuestra que la descripción de las reglas y estrategias que, según el informe de los sujetos, habían regido su selección, no son sino una racionalización construida a posteriori. Las reglas y razones que realmente han determinado su elección, permanecen fuera del ámbito de la conciencia del sujeto.

La evidencia manejada por Evans y Wason no parece ser la única existente. La revisión de un amplio rango de datos, dentro del campo de la psicología social y cognitiva, realizada por Nisbett y Wilson (1977), les lleva a establecer una conclusión esencialmente idéntica. A partir de una comparación de informes verbales retrospectivos con otros criterios de conducta, Nisbett y Wilson encuentran que muchas veces los sujetos desconocen: a) la existencia de estímulos que resultan críticos; b) la existencia de una respuesta; o c) que un estímulo ha provocado una respuesta. Sin embargo, en nuestra vida diaria, solemos responder a las preguntas acerca de los procesos cognitivos que subyacen a nuestras conductas de elección, evaluación, resolución de problemas, etc. Por eso, Nisbett y Wilson concluyen que cuando la gente intenta informar sobre los procesos cognitivos que mediaron los efectos de un estímulo sobre una respuesta, no lo hace en base a una verdadera introspección: no consulta la memoria. Por el contrario, lo hace en base a teorias causales apriorísticas o construidas como explicaciones plausibles de su conducta. Según eso, sólo tendrán lugar informes correctos cuando incidentalmente coincida que los estímulos y mecanismos determinantes resulten sobresalientes y constituyan causas plausibles de las réspuestas resultantes.

La conclusión tanto de Evans (1980 a y b) como de Nisbett y Wilson (1977) parece, cuando menos, demasiado pesimista; y seguramente sobregeneralizadora. En el caso de Evans, aun aceptando que en los experimentos en que se basó los sujetos estaban racionalizando, ello constituye una base muy débil para un rechazo general de los informes de estrate- 


\section{Estudios}

gias. Además, como sugiere Morris (1981 b), dichos experimentos ofrecen algunas dudas metodológicas y de interpretación.

En el experimento de Wason y Evans (1975), la conclusión se basa en un $\mathbf{N}$ muy pequeño: cinco sujetos; en segundo lugar, las tareas positiva y negativa no son propiamente iguales, asunción que constituía una condición fundamental para la conclusión; por último, las tareas parecen demasiado difíciles - la mayor parte de los sujetos no llegan a resolverlas-, por lo que cabe la posibilidad de que los pocos sujetos que dieron la respuesta correcta, al exigirles que la justificasen, estuvieran elucubrando sobre una elección que resultó buena accidentalmente. En el experimento de Evans y Wason (1976), la evidencia en contra de los informes de estrategias resulta aún más endeble: a los sujetos no se les estaba pidiendo que informaran de reglas y estrategias por ellos utilizadas, sino que justificaran una solución incorrecta presentada como correcta por el experimentador. Teniendo en cuenta la considerable presión social que suele producirse en estas situaciones, y lo difícil de una tarea que seguramente les resultaba insoluble, no tiene nada de extraño que los sujetos racionalizasen de la forma que lo han hecho. Todo ello dice poco acerca de los informes de estrategias en general.

Algo parecido ocurre con los datos revisados por Nisbett y Wilson (1977). Prácticamente, su evidencia nunca se refiere a los "procesos cognitivos", al menos tal como aquí los entendemos. Una parte de sus datos se refiere a la ausencia de conciencia para el pro: ducto final de procesos cognitivos rápidos y automatizados; y casi todo el resto, a la ausencia de conocimiento introspectivo de las causas, en general profundas, de conductas tales como los cambios de actitud, juicio estimativo, estado emocional, altruismo, etc. Es evidente que los sujetos humanos no conocen las causas y razones de toda su conducta; de haber sido así, apenas si tendría razón de ser la investigación psicológica.

Sin embargo, Nisbett y Wilson (1977) reconocen que los individuos tienen acceso directo a una gran cantidad de "hechos privados». Entre otras cosas, «conocen aquello que en cada momento constituye el foco de su atención (...) y tienen lo que casi todos los psicólogos y filósofos afirmarían ser un "conocimiento" al menos cuantitativamente superior al de los observadores respecto a sus emociones, evaluaciones y planes. (...) Frecuentemente, son capaces de describir los re- sultados intermedios de una serie de operaciones mentales» (pág. 255).

Es cierto que Nisbett y Wilson no consideran ni los planes y estrategias, ni la secuencia de resultados y etapas intermedios, como "proceso». Por ejemplo, el hecho de que en el problema del péndulo, uno de los sujetos de Maier (1931) se haya servido de las imágenes de los monos balanceándose en las ramas, no lo consideran como proceso mental hacia la solución. Tampoco consideran proceso el hecho de que, para recuperar de la memoria el apellido de soltera de su madre, un sujeto americano recurra a pensar en el primer apellido de su tío materno, de quien el sujeto sabe que conserva el apellido familiar que su madre tenía de soltera. Por nuestra parte, tenemos que reconocer que si lo anterior no constituye el proceso, o parte del proceso mental seguido por el sujeto, desconocemos qué pueda entenderse por proceso. Es cierto que puede referirse la concepción de "proceso" a niveles más básicos, pudiendo rebajarse hasta las operaciones físicas o bioquímicas que tienen lugar en las neuronas; pero por descontado que ese no sería el nivel más adecuado en el que podríamos describir con eficacia la conducta de los sujetos, y en todo caso, no estaríamos hablando de un proceso cognitivo, sino de un proceso de otro tipo, que desde luego no resulta accesible a la introspección, pero que tampoco constituye el objeto de investigación de nuestra disciplina.

En todo caso, nosotros coincidimos con Nisbett y Wilson en que en ocasiones los sujetos pueden tener conciencia de los planes y estrategias que gobiernan su actuación, y como tales planes y estrategias, para nosotros constituyen una forma de proceso cognitivo: precisamente el que en este apartado nos interesa. Por ejemplo, en tareas como las de criptoaritmética, hemos podido observar (Froufe, 1982) que mientras unas veces los sujetos se proponen resolver el problema DONALD + GERALD = ROBERT recurriendo a la asignación aleatoria de dígitos a letras, otras veces intentan resolverlo mediante ecuaciones de segundo grado, y otras, simplemente, aprovechando la información aritmética y la deducción lógica que indirectamente proporciona la situación problema.

De hecho, varios autores han recurrido a los informes verbales de los sujetos para descubrir las estrategias y mecanismos mentales que subyacen a su actuación en tareas de aprendizaje-memoria (Hunter, 1964; Luria, 1968) y de resolución de problemas (Quinton 


\section{6}

y Fellows, 1975; Hitch y Baddeley, 1976) ante situaciones que permiten cierta flexibilidad en su aproximación.

Unter (1964) trabajó con la memorización del "cuadrado mágico", en el que los nueve dígitos se disponen en tres filas $(4,9,2 ; 3,5,7$; $8,1,6)$, de tal forma que suman 15 todas las filas, columnas y diagonales. Después de obtener informes de más de 200 sujetos que estudiaron el cuadrado por un minuto y luego lo reprodujeron una hora más tarde, Hunter resalta que «difícilmente dos estudiantes cualesquiera llevaron a cabo la actividad de aprendizaje de la misma forma» (pág. 24). Algunos basaron su recuerdo fundamentalmente en la búsqueda y/o reconocimiento de relaciones significativas entre los números, bien sea el hecho de que se trata de un cuadrado mágico, bien el hecho más simple de que todas las columnas suman 15 , o que 4,9,2 constituyen las tres últimas cifras del año en que Colón descubrió América, o que la segunda fila incluye tres impares consecutivos, etc. Otros sujetos, por el contrario, se dedicaron a repetir mecánicamente los números con la finalidad de retenerlos hasta el momento de reproducirlos. Sin el informe por parte de los propios sujetos, no habríamos podido conocer la estrategia a que cada cual recurrió para aprender y recordar la matriz.

Algo parecido ocurre con las estrategias memónicas empleadas por el experto, objeto del detallado estudio de Luria (1968). Este autor, a partir del análisis de un caso individual, y basándose fundamentalmente en informes introspectivos del sujeto, descubre diferentes estrategias a las que aquél recurre para la ejecución de distintas tareas de memorización.

Quinton y Fellows (1975), pidiendo a los sujetos periódicamente, a lo largo de una serie de 112 problemas de tres-términos, que verbalizasen sus procesos de pensamiento y explicasen cómo estaban resolviéndolos, encontraron que mientras todos los sujetos comenzaban por referirse a una estrategia consistente en pensar en el significado de las premisas antes de responder al problema («thinking strategies»), gran parte de los mismos acabaron por abandonar - según sus propios informes- esta estrategia a favor de otra más eficaz. La nueva estrategia consistía en tener en cuenta ciertas características invariantes de la situación, ignorando total o parcialmente el significado de las premisas («perceptual» strategies). Una prueba subsiguiente con otros sujetos mostró que cuando

\section{Estudios}

se les inducía a usar la estrategia perceptual desde el primer momento, resolvían los problemas más rápidamente que si la hubieran tenido que descubrir por sí mismos. Ello sugiere que el informe verbal dado por los sujetos en la primera ocasión respondía a la realidad: mientras decian emplear una estrategia de pensamiento cuando su ejecución resultaba poco eficaz, cuando resultaba más eficaz hablaban de una estrategia perceptual.

Bien es verdad que esta evidencia resulta insuficiente, ya que está basada principalmente en el hecho de que dos sujetos distintos a los primeros, que fueron entrenados por los propios autores para que usasen la estrategia perceptual, produjeron la solución de los 112 problemas en un tiempo sensiblemente inferior al de cualquiera de los sujetos de la primera fase, que tuvieron que descubrir dicha estrategia por sí mismos. En realidad, lo que tendría que haberse hecho es comparar dos grupos entrenados mediante "contacto ciego" en el uso de las dos estrategias, y predecir una diferencia en el tiempo de solución. $\mathrm{Y}$ aun en este caso, aunque los datos resultaran positivos, siempre restaría (como señala Evans, 1976) la duda razonable de si la información de las estrategias se debe a una verdadera introspección, o a que la racionalización de los sujetos les ha llevado a explicar su conducta mediante un proceso que coincide con el que realmente ha tenido lugar. Sin embargo, de haber existido, dicha evidencia habria hecho más autorizada la conclusión de Quinton y Fellows (1975), en la que afirman "sentir" que "el presente estudio ha demostrado el valor de obtener información introspectiva de los sujetos respecto a sus propios procesos de pensamiento» (pág. 78).

Por último, en una de sus numerosas pruebas de razonamiento verbal, Hitch y Baddeley (1976), inmediatamente antes de la presentación de cada problema de verificación, presentaban de forma oral a sus sujetos una lista de seis consonantes, que debían reproducir una vez resuelto el problema. Además, mientras a la mitad de los sujetos se les decía que su ejecución (corrección y rapidez) en la tarea de razonamiento sería considerada únicamente si recordaban correctamente las seis letras (énfasis en la tarea de memoria), a la otra mitad, simplemente se les pedia que realizaran lo más rápida y correctamente posible ambas tareas (énfasis equiparable). Todos los miembros del primer grupo dijeron haber usado la simple estrategia de repetir rápidamente los items de la tarea de recuerdo, antes 


\section{Estudios}

de ponerse a resolver cada problema de verificación. En cambio, ninguno de los sujetos del otro grupo informó haber operado antes con una tarea que con la otra. Aunque desde luego los informes de los propios sujetos podrían estar sesgados por la influencia de las instrucciones recibidas, o constituir una simple racionalización, a través de las latencias para la verificación y de la eficacia para la reproducción de las consonantes, Hitch y Baddeley creyeron obtener alguna evidencia de que los mismos reflejaban el proceso real seguido por cada sujeto.

De la somera revisión precedente se desprende la impresión de que ni somos siempre conscientes de los procesos cognitivos que subyacen a nuestra conducta manifiesta, ni tampoco nos pasan desapercibidos todos. Por eso nos parece insostenible una postura antimentalista radical como la defendida no sólo por algunos conductistas modernos (Skinner, 1972), sino incluso por cognitivistas como Pylyshyn (1973). De hecho, la mayor parte de los psicólogos cognitivistas actuales (Wason y Johnson-Laird, 1972; Norma, 1976; Kosslyn y Pomeranzt, 1977; Morris, 1981 a y b; entre otros, por no hacer interminable la lista) consideran que los informes introspectivos pueden resultar, en ocasiones, de gran utilidad para el descubrimiento de los procesos psicológicos, y admisibles como evidencia "corroborativa» para su verificación. Por tanto, la atención de la investigación debe desplazarse desde la cuestión de si existe o no acceso introspectivo a los procesos, a la cuestión más fructífera de cuándo existe dicho acceso.

El problema radica en que, hasta la fecha, nadie parece tener un criterio operativo e inequívoco para decidir qué procesos son introspectibles y cuáles no. Bien es verdad que el problema de la seguridad absoluta no es patrimonio exclusivo de este método: también atañe a la experimentación estándar. No obstante, nosotros no rechazamos, por e jemplo, la investigación sobre aprendizajememoria porque no dispongamos de un criterio infalible para saber cuándo un sujeto retiene un item que podía haber dicho, o cuándo deja de presionar una tecla que debería haber presionado, etc. Ahora bien, en cualquier caso, es indispensable establecer las condiciones bajo las que una técnica de medición resultará aceptablemente fidedigna.

En este sentido, Smith y Miller (1978) sostienen que ulas tareas que resultan novedosas y de interés para los sujetos, tal como elegir colegio o resolver un problema desafiante, frecuentemente parecen evocar un conocimiento introspectivo preciso del proceso" (pág. 361). Smith y Miller basan en parte su suposición en el concepto de procesamiento de información controlado de Schneider y Shiffrin (1977), quienes lo refieren a las operaciones mentales efectuadas sobre contenidos atendidos, y que por tanto entran en la MCP. Shiffrin y Schneider (1977) hablan de estas operaciones como de procesos de control, entre los que incluyen "decisiones de todo tipo, repetición, codificación y búsqueda de los almacenes a corto y largo plazo" (pág. 155).

Ya hemos dicho que el procesamiento de información controlado, en la medida en que se refiere a contenidos que están disponibles en la MCP, implica conciencia de los mismos. Pero iresultan también accesibles a la conciencia los propios procesos de control? Según Shiffrin y Schneider (1977), "no todos los procesos de control están disponibles para la percepción consciente, y no todos pueden ser manipulados mediante instrucción verbal. Es, por tanto, conveniente dividir los procesos de control en dos clases: accesibles y velados. Los procesos de control accesibles son aquellos como la repetición rutinaria o la búsqueda alfabética en el ALP, que pueden ser establecidos y modificados mediante instrucción; éstos son generalmente procesos lentos que resultan fácilmente percibidos por el sujeto. Los procesos de control velados son aquellos como la comparación serial de items en el ACP, que resultan difíciles de modificar mediante instrucción; éstos no resultan fáciles de percibir mediante la introspección, porque tienen lugar muy rápidamente» (pág. 159). Por tanto, según esta postura, se podría decir que lo que es verdad para la activación de la información en general, lo es también para los procesos de control: el que sean accesibles o no depende de su naturaleza, principalmente de la rapidez con que tengan lugar.

Para Morris (1981 a), somos conscientes de los procesos controlados por el "procesador central» (BOSS), que para él consistirían básicamente en los planes y estrategias intencionadamente elegidos. El problema radica en que este criterio de intencionalidad, por subjetivo, al igual que la conciencia, resulta de difícil, si no de imposible, aplicación. En consecuencia, aun aceptando que se tratara de un supuesto teórico correcto, no resulta factible utilizarlo como base operativa para discriminar entre los procesos de los que podemos informar 


\section{8}

introspectivamente y aquellos que no resultan accesibles a la introspección.

Por nuestra parte, consideramos que la aproximación más eficaz para saber cuándo los auto-informes (tanto de los contenidos como de las estrategias) resultarán válidos, consiste en comenzar por integrar las circunstancias y procesos que intervienen en su producción, dentro del marco conceptual de la teoría del procesamiento de información humana; como lo hicieron en su espléndido trabajo Ericsson y Simon (1980). De la habilidad para conseguir lo anterior, dentro de una teoría cognitiva adecuada, depende nuestra capacidad para estimar el valor de los informes verbales como datos que reflejan la realidad cognitiva subyacente.

\section{LOS INFORMES VERBALES COMO DATOS}

Debido al descrédito del método introspectivo, los informes verbales han venido siendo sistemática y globalmente desechados como datos en psicología experimental. No obstante, ya hemos visto que, recientemente, algunos cognitivistas han vuelto a recurrir a los mismos para descubrir los procesos mentales que tienen lugar durante la realización de diferentes tareas de cognición. Ello ha dado lugar a la aparición de diferentes tipos de informes, cuyas características es necesario analizar antes de desecharlos en bloque como variantes del método introspectivo clásico.

Sin duda, el análisis más refinado y completo realizado dentro del marco de la teoría del procesamiento de la información sobre el particular, es el desarrollado por Ericsson y Simon (1980) en su artículo Verbal Reports as Data. Por eso, a continuación, nos limitaremos fundamentalmente a reproducir de forma extractada el modelo teórico presentado en dicho trabajo.

\section{a) Procedimientos de verbalización}

La única característica en común entre las diferentes técnicas y circunstancias para obtener datos verbales consiste en que el sujeto responde oralmente a una instrucción o sondeo por parte del experimentador. Por lo demás, las verbalizaciones pueden variar en función de diferentes parámetros. Uno de ellos depende del intervalo entre el momento de adquisición y el de reproducción de la información: verbalización concurrente si la información es reproducida en el momento en que es atendida, y verbalización retrospectiva si es reproducida más tarde. Es de esperar que lo que se recuerde depende de forma crítica de este intervalo.

Dentro de las verbalizaciones concurrentes, pueden distinguirse algunas variaciones en función del tipo de sondeo utilizado. Uno de los procedimientos más directos para obtener un trazado de la información atendida, y por tanto de las etapas internas del proceso cognitivo, consiste en pedir al sujeto que piense en voz alta mientras realiza una tarea. Otro procedimiento concurrente consiste en pedir al sujeto información específica que va surgiendo de la tarea; usualmente información clave para el subsiguiente desarrollo de la misma, como es el caso de las hipótesis empleadas para resolver un problema de formación de conceptos.

Dentro de los sondeos retrospectivos, puede distinguirse entre los que instan al sujeto para que refiera la información inmediatamente después de haber tenido lugar el proceso que la produjo, y los que, por referirse a situaciones que implican un cierto número de ensayos, resultan bastante más diferidos. Este último procedimiento está a veces justificado para eliminar cualquier interferencia de la introspección sobre el proceso «real». Lo que ya resulta más peligroso y difícil de justificar, desde un punto de vista científico riguroso, es pedir a un sujeto que nos dé información acerca de un proceso después que han transcurrido muchas cosas y tiempo desde que éste tuviera lugar. Y sin embargo, éste ha sido el caso del método muchas veces utilizado para estudiar el proceso creativo, al pedir a los creadores que hablen de sus viejos inventos y teorias.

El tipo de verbalización depende también de los procesos, sobre todo de recodificación, que intervienen entre el momento que la información es atendida por el procesador central y la generación de la verbalización correspondiente. En palabras de Ericsson y Simon (1980), «cuando la información es reproducida en la forma en que ha sido adquirida desde el procesador central, hablaremos de verbalización directa o de Nivel 1. Cuando ocurre uno o más procesos entre la atención a la información y su liberación, hablaremos de verbalización codificada de Nivel 2 o Nivel 3» (pág. 219).

En efecto, cuando la representación interna en la que está originalmente codificada la información no consiste en un código verbal, es 
preciso una recodificación a un código verbal (verbalización de Nivel 2). Y cuando se pide la verbalización de únicamente un tipo seleccionado de contenido dentro del conjunto de información atendida, son necesarios procesos adicionales de filtraje-rastreo que comprueben recurrentemente si la información seleccionada para la verbalización responde al tipo deseado (verbalización de Nivel 3). Otro tipo de verbalización de Nivel 3 ocurre cuando a un sujeto se le pide que refiera información que, de no haber sido por la instrucción de verbalizar, no habría sido atendida, como sucede normalmente cuando se le pide que describa sus propias actividades motrices. Algo parecido ocurre cuando a un sujeto se le pide que exponga las razones de su conducta manifiesta, con el agravante de que en este caso, cuando tales razones no resultan directamente accesibles - lo que puede ocurrir con frecuencia-, se le está induciendo a recurrir a procesos inferenciales. Por último, también muchas veces, en las verbalizaciones retrospectivas en general (en las que no suele pedirse al sujeto que recuerde instancias específicas de sus procesos cognitivos, sino que refiera sus procesos mentales en experimentos con muchos ensayos, o que respondan a cuestiones genéricas), se le está obligando a hacer abstracción de la información disponible. Todos estos auto-informes dan lugar a una verbalización de Nivel 3.

A diferencia de las cuestiones generales, que suelen inducir en el sujeto procesos inferenciales y de abstracción ( $y$ no hay que olvidar que la teorización sobre su conducta y procesos corresponde únicamente al experimentador), las preguntas específicas, al interesarse por aspectos más particulares de la conducta, buscan información que, de estar disponible, resulta más directamente accesible para el sujeto. Ahora bien, para obtener del sujeto esa información, frecuentemente las propias cuestiones del sondeo incluyen información contextual. Ello no debe impedir, pese a todo, la neutralidad necesaria para que la información obtenida resulte válida. Para conseguirlo, habrá que recurrir a preguntas indirectas, a proponer varias respuestas alternativas, o a cualquier otro procedimiento disponible, según las circunstancias.

En resumen, los parámetros en función de los que se pueden clasificar las verbalizaciones pueden integrarse en dos ejes básicos: tiempo de verbalización (fundamentalmente verbalizaciones concurrentes o retrospectivas) y relación entre la información atendida y la verbalizada. En este sentido, las verbalizaciones pueden implicar bien la articulación directa de información almacenada en código verbal (Nivel 1), bien la articulación, previa recodificación verbal, de información no proposicional, sin otros procesos adicionales (Nivel 2), o bien la articulación de la información disponible, una vez que ha sido tratada mediante procesos de filtraje, inferencia, generación o abstracción (Nivel 3).

\section{b) El modelo de procesamiento: Procesos de verbalización}

Una importante contribución de Ericsson y Simon (1980) consiste en que en su trabajo desarrollan un modelo bastante detallado para explicar cómo se generan los informes verbales, lo cual puede ayudar a interpretar la relación entre este tipo de datos y los procesos cognitivos que tienen lugar durante la ejecución de la tarea objeto de estudio.

Su modelo está basado en la teoría del procesamiento humano de la información, y, como tal, la hipótesis más general y básica sostiene que la cognición humana (y los procesos de verbalización lo son) consiste en procesamiento de información. Dentro de este modelo, «una asunción importante y más específica es que la información es almacenada en varias memorias, que tienen diferentes capacidades y características de acceso: varios almacenes sensoriales de corta duración, una memoria a corto plazo (MCP) con capacidad limitada y/o duración intermedia, y una memoria a largo plazo (MLP) con una considerable capacidad y un almacenaje relativamente permanente, pero con fijación y tiempos de acceso lentos comparada con las otras memorias" (pág. 223).

La información recibida a través de los órganos sensoriales permanece durante un corto período de tiempo en las memorias asociadas con los diferentes sentidos (RS). Parte de esta información sensorial es transferida a la MCP gracias a que, durante el tiempo que permanece en los RS, es reconocida y codificada directamente por el procesador central, valiéndose de la información (patrones) existente en la MLP. Esta información recién adquirida y atendida en la MCP resulta directamente disponible para procesamientos subsiguientes, por ejemplo, para producir informes verbales.

Por otra parte, una porción del contenido de la MCP, a través de operaciones de repaso, asociación, codificación con procesamiento profundo..., es fijada, antes de que desaparezca, en la MLP. En ocasiones, esta informa- 
ción puede ser recuperada con posterioridad, pero previamente ha de ser transferida de nuevo, a través de procesos asociativos, a la MCP.

Así, pues, la información puede llegar a la MCP desde los RS a través de los procesos directos de reconocimiento, o desde la MLP a través de procesos de asociación. Ahora bien, estos últimos procesos resultan mucho más lentos que los anteriores, y lo que es más decisivo, menos fiables, ya que la recuperación de la información desde la MLP puede conducir a recordar datos relacionados, pero inadecuados. Por otra parte, tampoco todo lo que se recupera de la MLP pasa por la MCP. La recuperación de información familiar, a no ser que requiera recuerdo a través de asociaciones sucesivas, frecuentemente deja en la MCP sólo el trazo del resultado final. Se trata de procesos de recuperación directa debidos a la automatización desarrollada con la práctica.

De todo lo anterior, cabe destacar un principio fundamental para el tema que nos ocupa: sólo la información contenida en la MCP está directamente disponible para procesos subsiguientes. En consecuencia, dada la capacidad limitada de la MCP, sólo la información que ocupó más recientemente nuestra atención podrá ser transmitida directamente a través de informes verbales. Sin embargo, ya hemos visto que la transmisión verbal de la información implicada en nuestros procesos cognitivos depende además de una segunda dimensión: relación en cuanto a tipo de codificación y procesos de tratamiento intermedios, entre la información atendida por el procesador central a lo largo de la realización de la tarea y la información verbalizada. Las verbalizaciones que requieren una recodificación verbal previa (Nivel 2) o procesos de filtraje, inferencia, etc. (Nivel 3) pueden no sólo lentificar, sino incluso distorsionar el proceso en sí, o al menos constituir un reflejo desvirtuado del mismo. En consecuencia, es de prever que sólo los informes verbales referidos a datos almacenados en la MCP en forma esencialmente proposicional generarán información intrinsecamente válida.

\section{c) Predicciones especificas}

\section{Verbalizaciones concurrentes}

Según el modelo anterior, al asumir que, en el procedimiento de pensar-en-voz-alta, la información verbalizada es una porción de la información que está siendo atendida, es de esperar que:
- Si los elementos de información en la MCP ya denotan símbolos de tipo verbal (representan cadenas de fonemas), podrán ser verbalizados automáticamente sin que ello suponga una demanda adicional decisiva para el sistema. Por tanto, se considera que en tales casos los protocolos resultantes aportan datos válidos, ya que, además de reflejar en buena parte la información realmente manejada, la instrucción de verbalizar no tiene por qué afectar de forma sustancial ni la estructura ni el curso y ritmo de los procesos cognitivos.

- Si la información atendida en la MCP no está verbalmente codificada (por ejemplo, imágenes visuales), el pensar-en-voz-alta requiere un proceso de recodificación que supondrá algunas exigencias adicionales, aunque sean leves, sobre los recursos y tiempo de procesamiento. Sin embargo, para Ericsson y Simon (1980), aunque esto signifique que cuando procesos prioritarios para la realización de la tarea interrumpan la recodificación verbal, alguna información activada en la MCP pueda no ser vocalizada, o que el ritmo de ejecución pueda verse ligeramente lentificado, la producción del protocolo verbal no alentará severamente ni el curso ni la estructura del proceso de actuación; a no ser que se trate de información muy difícil de recodificar.

Por último, si a los sujetos se les pide que expliciten información que para ser especificada necesita previamente ser elaborada por procesos de filtraje, abstracción, inferencia, etc. (lo cual seguramente les exige atender a aspectos que da otra forma habrían pasado desapercibidos), la producción verbal podrá alterar el curso y estructura del proceso cognitivo, $o$, al menos, no refle jarlo con la veracidad mínima indispensable. Por eso, los datos contenidos en los protocolos generados en estas circunstancias resultan de validez muy dudosa a la hora de establecer la realidad cognitiva subyacente. Eso no quiere decir que carezcan de todo valor, siempre que se utilicen de forma prudente y dentro de un contexto meramente de descubrimiento.

\section{Verbalizaciones retrospectivas}

$\mathrm{La}$ validez de los informes restrospectivos para esclarecer la realidad cognitiva que subyace a la conducta manifiesta, resulta cuando menos problemática e incierta, dependiendo de factores como el tiempo transcurrido entre la ocurrencia del proceso y su referencia verbal, duración del proceso mismo, tipo de tarea o codificación de la información, generalidad-especificidad del sondeo, etc. 


\section{Estudios}

Desde luego, el sondeo retrospectivo más común es el que pide a los sujetos que digan todo lo que recuerden acerca de lo que ocurrió. Si al sujeto se le pregunta inmediatamente después de que ha tenido lugar la conducta, el modelo predice que algunos elementos previamente atendidos permanecerán aún en la MCP. Por tanto, aquellos resultarán directamente accesibles, y además facilitarán, por asociación, la recuperación de la MLP de algunos datos adicionales. De todas formas, el grado en que los informes retrospectivos dependan de la recuperación de información de la MLP puede minimizarse estudiando procesos cognitivos de corta duración.

De no darse condiciones óptimas, los informantes retrospectivos podrían no sólo proporcionar información incompleta, sino también originar información que no corresponde con la realidad.

\section{d) Evidencia empírica}

Por último, Ericsson y Simon (1980 y 1981) proceden a revisar la evidencia empírica que consideran más relevante para el modelo. $\mathrm{La}$ analizan desde tres perspectivas: a) Los efectos de la instrucción de verbalizar sobre el proceso cognitivo, b) lo completo de los informes verbales, y c) la consistencia de los informes verbales con otros datos empíricos no-verbales.

Aunque el modelo podría considerarse más fidedignamente validado de haber sido sus implicaciones contrastadas con un nuevo cuerpo de investigaciones directamente diseñadas para someterlo a prueba, del agudo análisis de un buen número de estudios que en la mayor parte de los casos sólo indirectamente fueron pensados $\longrightarrow$ o sólo indirectamente pueden utilizarse - para cotejar alguna predicción relevante para dicho modelo, Ericsson y Simon creen haber obtenido un sustancial apoyo para el mismo. Los informes verbales inadecuados encontrados por otros autores (parte de ellos revisados por Nisbett y Wilson, 1977) serían el resultado de pedir información que nunca estuvo directamente en el foco de la atención (MCP); o que, aun habiendo estado, debido al tiempo transcurrido hasta el informe $\mathrm{y} / \mathrm{o}$ a los procesos que deben tener lugar para generarlo, los sujetos producen informes incompletos, y más bien se dedican a inferir que a recordar los datos aportados.

Como puede verse, de nuevo la incógnita mayor se refiere a la capacidad de los sujetos para informar verbalmente de las causas, estrategias y reglas que rigen sus respuestas. El modelo de Ericsson y Simon (1980) es incapaz de hacer predicciones fuertes al respecto, ya que no dispone de ningún criterio operativo para saber cuándo el sujeto dispone o no directamente de aquella información en la MCP. Por tanto, no se puede saber a ciencia cierta, a partir del modelo, cuándo un informe verbal sobre estrategias responde a una auténtica introspección y cuándo constituye una mera racionalización a posteriori. Semejante imprecisión se debe, básicamente, a la falta de. desarrollo de la teoría general de procesamiento humano de información. Creemos, pues, que no existe de momento el marco teórico adecuado en psicología cognitiva para dar una respuesta general y objetiva a esta cuestión.

\section{A MODO DE CONCLUSION}

La primera conclusión más elemental se refiere al hecho de que ni los productos de los procesos cognitivos resultan siempre accesibles a la introspección, ni los procesos mismos resultan siempre inaccesibles. Tanto si entendemos "proceso" como una secuencia de contenidos, como si lo entendemos como las estrategias o mecanismos que rigen nuestra actuación.

La posibilidad de falta de conciencia para el resultado de un proceso cognitivo queda puesta de manifiesto en los diversos experimentos de percepción subliminal (Smith y col., 1959; Henley y Dixon, 1974; Philppott y Wilding, 1979) y discriminación preatencional del significado de palabras (Corteen y Dun, 1974; Von Right y col., 1975; Underwood, 1976). La evidencia a favor de la posibilidad de conciencia para los procesos entendidos como contenidos y etapas intermedias, la aportan investigaciones como las de Dean y Martin (1966), Newell y Simon (1972), o Wood, Shoter y Godden (1974). Este constituye además un hecho no discutido. Mucho más discutida resulta la cuestión de si los sujetos humanos pueden no tener conocimiento de las reglas y estrategias que conforman sus procesos mentales. Una serie de datos (Quinton y Fellows, 1975; Hitch y Baddeley, 1976; Froufe, 1982) nos ha hecho concluir que en ocasiones los sujetos sí son conscientes de algunas estrategias que guían su actuación cognitiva.

En consecuencia, la cuestión no parece consistir tanto en demostrar que somos conscientes de los productos, pero no de los procesos cognitivos, cuanto en investigar cuánto somos 
conscientes, y cuánto no, de los procesos y de sus productos.

Concretamente, tenemos conocimiento de los productos finales de nuestros procesos cognitivo-perceptuales sólo cuando se trata de estimulación supraliminal a la que atendemos. En el caso de los procesos cognitivos necesarios para enfrentarse a situaciones nuevas, procesos que requieren control activo $y$ atención por parte del sujeto, no sólo existe conocimiento del producto final, sino también de contenidos y etapas intermedios. Sin embargo, no existe acuerdo a la hora de caracterizar las circunstancias que determinan la existencia de conciencia para los procesos entendidos como estrategias.

Para Shiffrin y Schneider (1977), resultarän conscientes cuando se trata de operaciones mentales lentas que exigen un control activo por parte del sujeto, es decir, las operaciones mentales necesarias para enfrentarse a tareas nuevas y complejas. Sin embargo, Nisbett y Wilson (1977), y Evans (1980 b), ponen en duda semejante criterio, ya que entienden que lo que los sujetos interpretan como reglas que guiaron su conducta no son sino racionalizaciones desarrolladas a partir de lo que serían explicaciones plausibles de la misma. El criterio de Morris (198 a), según el cual tendríamos conciencia de aquellas estrategias y planes mentales que adoptamos voluntariamente, resulta de una aceptabilidad teórica considerable, pero de escasa o nula operatividad, por subjetivo.
Todo lo anterior tiene una implicación inmediata para el tema de los informes verbales como datos que nos permitan descubrir la realidad cognitiva que subyace a la conducta manifiesta. Ericsson y Simon (1980) sostienen que «los informes verbales, cuidadosamente suscitados e interpretados con plena comprensión de las circunstancias bajo las que fueron obtenidos, constituyen un origen de información acerca de los procesos cognitivos valioso y completamente fidedigno» (pág. 247). Concretamente los mencionados autores, a partir de la teoría de cómo se generan los informes verbales, sostienen que los mismos constituyen un reflejo aceptable de la información manejada, siempre que se basen en datos directamente disponibles en la MCP, sobre todo si dichos datos están verbalmente codificados. No obstante, la teoría general del procesamiento humano de información, en la que se basan Ericsson y Simon, tampoco dispone hasta la fecha de criterios operativos a priori para discriminar entre las operaciones mentales de las que somos conscientes y aquellas de las que no. Eso no impide que en casos aislados pueda verificarse, mediante otros datos no verbales, la coincidencia entre las operaciones referidas verbalmente y las operaciones realmente responsables de la conducta. Pero mientras no se disponga de un criterio a priori fiable, sólo será legítimo recurrir a los informes verbales como técnica auxiliar para descubrir (no para constatar) las operaciones mentales que integran los procesos cognitivos humanos.

\section{Bibliografía}

Atkinson, R. C., y Shiffrin, R. M.: «The control of short-term memory». Scientific American, 1971, 225, 82-89.

Berstein, R, y ERIKSEN, C. W.: «Subception: Fact or artifact?» Psychological Review, 1956, 63, $74-80$.

BEVAN, W., y PRITCHARD, J. F.: «Effect of "subliminal" tones upon the judgement of loudness". Journal of Experimental Psychology, 1963, 66, 23-29.

BLACK, R. W., y BEVAN, W.: "The effect of subliminal shock upon the judged intensity of weak shock». American Journal of Psychology, 1960, 73, 262-267.

Boardman, W. K., y Goldstone, S.: «Effects of subliminal anchors upon judgements of size». Perceptual and Motor Skills, 1962, 14, 475-482.

BRADSHAW, L.: «Peripherally presented and unreported words may bias the perceived meaning of a centrally fixated homograph". Journal of Experimental Psychology, 1974, 103, 1200-1202.

BRICKER, P. D., y ChAPANIS, A.: «Do incorrectly perceived tachistoscopic stimuli convey some information?". Psychological Reviewn 1953, 60, 181-188.

Broadbent, D. E., y Gregory, M.: «Perception of emotionally toned words». Nature, 1967, 215, 581-584.

BYRNE, R.: «Planning meals: Problem-solving on a real database». Cognition, 1977, 5, 287-332.

COBB, W. A.; MORTON, H. B., y ETTLINGER, G.: "Cerebral evoked potentials evoked by pattern reversal and their suppression in visual rivalry». Nature, 1967, 216, 1123-25.

CoRTeEn, R. S., y DunN, D.: "Shock associated words in a nonattended message: a test for momentary awareness». Journal of Experimental Psychology, 1974, 102, 1143-44. 
CORTEEN, R. S., y WOOD, B.: «Antonomic responses to shock associated words". Journal of Experimental Psycbology, 1972, 94, 308-313.

ChOMSKy, N.: Aspects of the theory of syntax. MIT Press. Cambridge, Mass, 1965.

DEAN, S. J., y MARTIN, R. B.: "Reported mediation as a function of degree of learning". Psychonomic Sciencie, $1966,4,231-32$.

Dixon, N. F.: Preconscious processing. John Wiley and Sons. Nueva York, 1981.

Froufe, M.: Rigidez mental y su incidencia en resolución de problemas. Tesis Doctoral. Universidad Atónoma. Madrid, 1982.

EAGLE, M.: "The effects of subliminan stimuli of aggresive content upon conscious cognition*. Journal of Personality, 1982, 27, 578-600.

ERICSSON, K. A., y SimON, H. A.: «Verbal reports as data». Psychological Review, 1980, 87, 215-251.

ERICSSON, K. A., y SimON, H. A.: «Sources of evidence on cognition: A historical overview». En: T. V. Merluzzi, C. R. Glass y M. Genest (eds.). Cognitive assessment. Guilford Press. Nueva York, 1981.

Evans, J. ST B. T.: "A critical note on Quinton and Fellows' observation of reasoning strategies». British Journal of Psychology, 1976, 64, 517-18.

EvanS, J. ST B. T.: «Current issues in the psychology of reasoning». British Journal of Psychology, 1980a, $71,227-39$.

EvanS, J. ST B. T.: «Thinking: experiential and information processing approaches». En: G. Claxton (Ed.). Cognitive psycbology: New directions. Routledge and Kegan Paul. Londres, $1980 \mathrm{~b}$.

Evans, J. ST B. T., y WASON, P. C.: «Rationalization in a reasoning task». British Journal of Psychology, $1976,67,479-86$.

FARNE, M: «Effects of so-called subliminal stimuli upon visual perception». Psychological Research Bulletin, 3 (Lund University), 1963.

FORSTER, P. M., y GOVIER, E.: "Discrimination without awareness?" Quarterly Journal of Experimental Psychology, 1978, 30, 282-95.

GUTHRIE, G., y WIENER, M.: "Subliminal perception or the perception of partial cues with pictorial stimuli». Journal of Personality and Social Psycbology, 1966, 3, 619-28.

Harter, M.; SEIPLE, W., y MUSSO, M.: «Binocular summation and suppression: Visually evoked cortical responses to dichoptically presented patterns of different spatial frequencies». Vision Research, 1974, $14,1169-80$.

HENLEY, S. H. A.: «Responses to homophones as a function of cue words on the unattended channel». British Journal of Psycbology, 1976, 67, 559-67.

HeNley, S. H. A., y DixON, N. F.: «Laterality differences in the effects of incidental stimuli upon evoked imagery". British Journal of Psychology, 1974, 65, 529-36.

HIRST Y OTROS: «Dividing attention without alternation or automaticity". Journal of Experimental Psychology, $1980,109,98-117$.

Hitch, C. J., y BADDLEY, A. D.: "Verbal reasoning and working memory». Quarterly Journal of Experimental Psychology, 1976, 28, 603-21.

Hunter, I. M. L.: Memory. Londres. Penguin, 1964.

Kosslyn, S. M., y POMERANTZ, J. R.: «Imagery, propositions and the form of internal representations». Cognitive Psychology, 1977, 9, 52-76.

Lazarus, R. S., y MCCLEARY, R. A.: "Antonomic discrimination without awareness: A study of subception». Psychological Review, 1951, 58, 113-22.

LehmanN, D.; Beeler, G. W. (jr.) y Fender, D. H.: "Changes in pattern of the human electroencephalogram during fluctuations of perception of stabilized retinal images».E. E. G. and Clinical Neuropbysiology, $1965,19,336-43$.

LEWISS, J. L.: «Semantic processing of unattended messages during dichotic listening». Journal of Experimental Psychology, 1970, 85, 225-28.

LEWIS, J. L.: «Semantic processing with bisensory information». Journal of Experimental Psychology, 1972, $96,445-47$.

LUNDH, L. G.: «Introspection, consciousness, an human information crocessing». Scandinavian Journal of Psychology, 1979, 20, 233-38.

LURIA, A. R.: The mind of a mnemonist. Nueva York. Basic Books, 1968.

MACKAY, D. G.: «Aspects of the theory of comprehension, memory and attention». Quarterly Journal of Experimental Psychology, 1973, 25, 22-40.

MAIER, N. R. F.: "Reasoning in humans. II: The solution of a problem and its appearance in consciousness». Journal of Comparative Psycbology, 1931, 12, 181-94.

MANDLER, G.: “Conciousness: Respectable, useful and probably necessary». En: R. Solso (ed.). Information processing and cognition: The Loyola Symposim. Erlbaum. Hillsdale, Nueva York, 1975.

Marcel, A. J., y PATterson, K. E.: «Word recognition and production: reciprocity in clinical and normal studies». En: J. Requin (ed.). Attetion and performance (vol. 7). Erlbaum. Hillsdale, Nueva York, 1978.

Miller, G. A.: Psychology: the science of mental life. Harper and Row. Nueva York, 1962.

MORRIS, P.: "The cognitive psychology of self-reports». En: C. Antaki (ed.). The Psychology of ordinary explanations of social behaviour. Academic Press. Londres, 1981 a.

MORRIS, P.: "Why Evans is wrong in criticizing introspective reports of subject strategies". British Journal of Psychology, 1981b, 72, 465-68. 
MYKEI, N., y DAVES, W. F.: «Emergence of unreported stimuli into imagery as a function of laterality of presentation: a replication and extension of research by Henley and Dixon». British Journal of Psycho$\log y, 1979,70,253-58$.

NeISSER, U.: Cognitive Psychology. Appleton Century Crofts. Nueva York. 1967.

NeISSER, U.: "The limits of cognition". En: P. W. Jusczyk y M. Klein (ed.): The nature of thought. Essays in bonor of $D$. 0 . Hebb. Erlbaum. Hillsdale, Nueva York, 1980.

Newell, A., y SimON, H. A.: Human problem solving. Pretince Hall, N. J., 1972.

NisberTT, R. E., y WILSON, T. D.: «Telling more than we can know: Verbal reports on mental processes». Psycbological Reviewn 1977, 84, 231-59.

Norman, D. A.: Memory and attention. Wiley, Nueva York Oó. ed.Gm 1976.

PHILPOT, A., y WILDING, J.: «Semantic interference from subliminal stimuli in a dichoptic viewing situation». British Journal of Psychology, 1979, 70, 559-63.

POSNER, M.: "Coordination of internal codes». En: W. Chase (ed.). Visual information processing. Academic Press. Nueva York, 1973.

PYLYSHYN, Z. W.: "What the mind's eye tells the mind's brain: A critique of mental imagery». Psychological Review. 1973, 80, 1-24.

Quinton, G., y Fellows, B. J.: "Perceptual" strategies in the solving of three-term series problem»». British Journal of Psychology, 1975, 66, 69-78.

REES, H. J., e ISRAEL, H. E.: «An investigation of the stablishment and operation of mental sets». Psychological Monographs, 1935, 46, 210 completo.

Riggs, L. A., y WhITTLE, P.: «Human occipital and retinal potentials evoked by subjectivily faded visual stimuli». Vision Research, 1967, 7, 441-51.

Ruiz, J. M., y Botella, J.: «Limitaciones de procesamiento y selectividad atencional». Estudios de Psicología, $1981,7,30-41$.

SARGENT, S.S.: "Thinking processes at various levels of difficulty". Archives of Psychology, 1940, $249,5-58$.

SCHANK, R. C., y ABELSON, R. P.: Scripts, plans, goals and understanding: An inquiry into buman knowledge structures. Eribaum. Hillsdale, N. J., 1977.

SCHNEIDER, W., y SHIFFRIN, R. M.: "Controlled and automatic human information processing: 1. Detention, search, and attention». Psychological Review, 1977, 84, 1-66.

SHEVRIN, H., y DiCKMAN, S.: "The psychological uncoscious. A necessary assumption for all psychological theory?" American Psychologist, 1980, 35, 421-34.

SHIFFRIN, R. M., y SCHNEIDER, W.: “Controlled and automatic human information processing: II. Perceptual learning, automatic attending, and a general theory». Psycholo Review, 1977, 84, 127-190.

Simon, H. A.: Models of thought. Yale University Press. Nueva Haven, 1979.

SKINNER, B. F.: Beyond freedom and dignity. Cape. Londres, 1972.

SMITH, M. C., y GROEN, M.: "Evidence for semantic analysis of unattended verbal items". Journal of Experimental Psychology, 1974, 102, 595-63.

SMITH, G. J., y Henriksson, M.: «The effect of an established percept of a perceptual process beyond awareness". Acta Psychologica, 11, 1955, 346-55.

SmITH, E. R., y MiLLER, F. D.: «Limits on perception of cognitive processes: A reply to Nisbett and Wilson». Psychological Review, 1978, 85, 355-62.

SMITH, G. J.; SPENCE, D. P., y KLEIN, G. S.: "Subliminal effects of verbal stimuli ». Journal of Abnormal and Social Psychology, 1959, 59, 167-76.

SOMEKH, D. E., y WILDING, J. M.: «Perception without awareness in a dichoptic viewing situation». Britisb Journal of Psychology, 1973, 64, 339-49.

SPENCE, D. P., y HOLLAND, D.: "The restricting effects of awareness: A paradox and an explanation". Journal of Abnormal and Social Psycbology, 1962, 64, 163-74.

STERNBERG, R. J.: Intelligence, information processing and analogical reasoning. Wiley. Nueva York, 1977.

UNDERWOOD, G.: «Semantic interference fron unattended printed words». British Journal of Psychology, $1976,67,327-38$.

VON WRIGHT, J. M.; ANDERSON, K., y STENMAN, U.: «Generalization of conditioned GSR's in dichotic listening». En: P. M. A. Rabbitt y S. Dorric (ed). Attention and performance. Academic Press. Nueva York, 1975.

WALlAS, R.: The art of thought. Harcourt Brace Jovanovich. Nueva York, 1926.

WARDLAW, K. A., y KROL, N. E. A.: "Automatic responses to shockassociated words in a nonattended message. A failure to replicate». Journal of Experimental Psychology. Human Perception and Performance, $1976,2,357-60$.

Wason, P. C., y Evans, J. ST B. T.: «Dual processes in reasoning?» Cognition, 1975, 3, $141-54$.

WASON, P. C., y Johnson-LAiRd, P. N.: Psychology of Reasoning: Structure and content. Batsford. Londres, 1972.

Williams, M. D., y Hollan, J. D.: «The process of retrieval from very long-term memory». Cognitive Science, $1981,5,87-119$.

WOOD, D. J., y SHOTTER, J. D.: "A preliminary study of distinctive features in problem solving». Quarterly Journal of Experimental Psycbology, 1973, 25, 504-10.

WOOD, D. J.; SHOTTER, J. D., y GodDEN, G.: «An investigation of the relationships between problem 


\section{Estudios}

solving strategies, representation and memory». The Quarterly Journal of Experimental Psychology, 1974, $26,252-57$.

WOODWORTH, R. S.: Experimental Psycbology. Holt. Nueva York, 1938.

WORTHINGTON, A. G.: «Effect of subliminal structural cues on reproductions of a simple line drawing». Perceptual and Motor Skills, 1964, 19, 823-82.

ZUCKERMAN, M.: "The effects of subliminal and supraliminal suggestion on verbal productivity». Journal of Abnormal and Social Psychology, 1960, 60, 404-11. 